\title{
Cholesterol and Affective Morbidity
}

\author{
Jess G. Fiedorowicz ${ }^{\mathrm{a}, \mathrm{d}}$, Narasimha M. Palagummi ${ }^{\mathrm{C}}$, Ole Behrendtsen ${ }^{\mathrm{a}, \mathrm{b}}$, and William $\mathbf{H}$. \\ Coryella \\ aDepartment of Psychiatry, Roy J. and Lucille A. Carver College of Medicine, The University of lowa, \\ lowa City, lowa \\ bDepartment of Internal Medicine, Roy J. and Lucille A. Carver College of Medicine, The University \\ of lowa, lowa City, lowa \\ 'Private Practice, Marshalltown Medical Clinic, Marshalltown, lowa
}

\begin{abstract}
Depression and mania have been linked with low cholesterol though there has been limited prospective study of cholesterol and subsequent course of affective illness. We studied the relationship between fasting total cholesterol and subsequent depressive and manic symptoms. A total of 131 participants from a prospective cohort study were identified as having had a fasting total cholesterol evaluation at intake. Participants were predominantly inpatients at index visit and were followed for a median of 20 and up to 25 years. Cholesterol was modeled with age, gender, and index use of a mood stabilizer in linear regression to assess its influence on subsequent depressive symptom burden in participants with unipolar disorder as well as depressive and manic symptom burden in participants with bipolar disorder. Among bipolar participants $(\mathrm{N}=65)$, low cholesterol predicted a higher proportion of follow-up weeks with manic, but not depressive symptoms. Cholesterol did not appear to predict depressive symptom burden among participants with unipolar depression $(\mathrm{N}=66)$. Lower cholesterol levels may predispose individuals with bipolar disorder to a greater burden of manic symptomatology and may provide some insight into the underlying neurobiology.
\end{abstract}

\section{Keywords}

Cholesterol; Major depression; Bipolar disorder; Mania; Depression

\section{Introduction}

Several case control and cross-sectional studies noted associations between low total cholesterol and depressive syndromes (Morgan et al., 1993; Glueck et al., 1994; Olusi and Fido, 1996; Maes et al., 1999; Partonen et al., 1999; Jow et al., 2006) though these findings have not been consistently replicated, particularly in Asian samples (Oxenkrug et al., 1983; Nakao and Yano, 2004; Chung et al., 2007). Low cholesterol has also been variably associated with suicide attempts (Golier et al., 1995; Coryell and Schlesser, 2007; Fiedorowicz and Coryell, 2007) and completions (Muldoon et al., 1990; Lindberg et al., 1992; Neaton et al.,

(C) 2009 Elsevier Ireland Ltd. All rights reserved.

dCorresponding author (JG Fiedorowicz). Address: 200 Hawkins Drive, W278GH, Iowa City, IA 52242, Phone: (319) 384-9267, Fax: (319)353-8656, jess-fiedorowicz@uiowa.edu.

Publisher's Disclaimer: This is a PDF file of an unedited manuscript that has been accepted for publication. As a service to our customers we are providing this early version of the manuscript. The manuscript will undergo copyediting, typesetting, and review of the resulting proof before it is published in its final citable form. Please note that during the production process errors may be discovered which could affect the content, and all legal disclaimers that apply to the journal pertain. 
1992; Ellison and Morrison, 2001). Interestingly, several studies have identified this association only in males (Golier et al., 1995; Bocchetta et al., 2001; Diaz-Sastre et al., 2007). Treatment of major depression increases total cholesterol (Gabriel, 2007) and lowdensity lipoprotein (LDL) cholesterol (Kopf et al., 2004) levels though not consistently (Deisenhammer et al., 2004). Papakostas and colleagues found those with higher cholesterol were less likely to respond to (Papakostas et al., 2003) and more likely to relapse on (Papakostas et al., 2004) antidepressants.

Patients with manic or mixed syndromes have also had lower cholesterol concentrations than controls in a number of studies (Swartz, 1990; Ghaemi et al., 2000; Atmaca et al., 2002; Cassidy and Carroll, 2002; Pae et al., 2004; Sagud et al., 2007). In one report, patients with bipolar disorder in remission likewise had lower cholesterol concentrations than controls (Atmaca et al., 2002). Other studies have found an excess prevalence of hyperlipidemia (Fagiolini et al., 2005; Fiedorowicz et al., 2008), however, in the form of hypertriglyceridemia rather than hypercholesterolemia. Treatment of manic symptoms appeared to reduce total cholesterol in one study (Gabriel, 2007), but increase it in another (Pae et al., 2004).

Bolstering the aforementioned findings, brain cholesterol levels are reduced with major depression and bipolar disorders compared with healthy controls (Beasley et al., 2005). Overall, published findings support a relationship between cholesterol and affective symptoms although inconsistencies in findings suggest this relationship may be complex. We are not aware of any studies that prospectively assessed the relationship between cholesterol and depressive symptoms for longer than one year (Papakostas et al., 2004) or that examined the relationship between cholesterol and manic symptoms. We used local data from our prospective cohort Collaborative Depression Study (CDS) to test our hypothesis that low total cholesterol levels would predict subsequent depressive and manic morbidity.

\section{Methods}

\subsection{Subjects}

Between the years 1978 and 1981, the CDS recruited English-speaking, Caucasian adults who met Research Diagnostic Criteria (Spitzer et al., 1978) for a major affective disorder. We identified 131 participants from the Iowa site of the CDS who had a fasting total cholesterol determination at study intake and were followed for at least 6 months thereafter. Fasting cholesterol determinations were not obtained as part of the CDS protocol though total cholesterol was routinely ordered as an admission lab during the period of CDS recruitment. The vast majority of participants in our sample had been recruited during an index inpatient admission. A few participants were outpatients at the time of intake. Participants in this sample have been followed for a mean (median; SD) of $15.7(20 ; 8.5)$ years and for up to twenty-five years.

\subsection{Procedures}

Baseline demographic and clinical information was obtained from intake data recorded on the Schedule for Affective Disorders and Schizophrenia (SADS) (Endicott and Spitzer, 1978) and the Personal History of Depressive Disorders (PHDD). One SADS item categorically estimated "total weight loss from usual weight during present episode (or maximum of 1 year) without dieting (even if later regained weight)." From this SADS item, we were able to identify participants that had subjectively lost 10 pounds or more, given the potential for meaningful changes in cholesterol with this degree of weight loss (Volek et al., 2002). Medical history was abstracted from the PHDD (available upon request). 
Follow-up assessments categorized severity of affective psychopathology using various forms of the Longitudinal Interval Follow-up Evaluation (LIFE) (Keller et al., 1987). The LIFE provided weekly ratings of symptom levels for each Research Diagnostic Criteria (RDC) syndrome and was administered semiannually for the first five years of prospective follow-up and annually thereafter. An initial diagnosis of unipolar depression was based on intake RDC diagnosis of major depressive disorder or schizoaffective-disorder, depressed, mainly affective (Endicott and Spitzer, 1979). The latter category approximates major depression as defined by the $4^{\text {th }}$ edition of the Diagnostic and Statistical Manual of Mental Disorders (DSM-IV). An initial diagnosis of a bipolar disorder was based on an intake RDC diagnosis of bipolar I, bipolar II, schizoaffective manic, or schizoaffective depressed with a history of mania or schizoaffective-mania, mainly affective. The latter category also approximates DSM-IVdefined mania. To utilize the most valid diagnoses, follow-up ratings from the LIFE Psychiatric Status Rating (PSR) were used to reclassify participants with unipolar depression, who develop their first mania or hypomania during follow-up (Fiedorowicz et al., 2008). To minimize misclassification, these prospective diagnoses were utilized in our analyses. Measures from the LIFE and SADS have been frequently applied to study course of illness and nosology in affective disorders (Judd et al., 1998; Coryell et al., 2003; Judd et al., 2003; Solomon et al., 2003).

PSR ratings were also used to determine the affective morbidity experienced by each individual. A week of clinically significant depressive symptoms was defined utilizing a PSR cutoff score of $>2 / 6$ (at least moderate symptoms) on the major depression or schizoaffective depression scale or a score of $3 / 3$ (definite criteria) for minor depression or intermittent depression. The burden of depressive morbidity was expressed as the proportion of follow-up weeks with clinically significant symptoms. A week of clinically significant manic symptoms was defined using a PSR cutoff score of $>2 / 6$ on the mania or schizoaffective mania scales or a score of $3 / 3$ for hypomania. These PSR cutoffs were selected based on clinical relevance in previously published work (Fiedorowicz et al., 2008). Akin to depressive morbidity, burden of manic morbidity was expressed as the proportion of follow-up weeks with any clinically significant (hypo)manic symptoms.

As aforementioned, blood samples for cholesterol were collected clinically at the time of intake, while seeking treatment for an affective episode, typically in an inpatient setting. This single, baseline total cholesterol value was utilized for all subsequent analyses. Dietary or nutritional assessments were not obtained. Use of lipid-lowering medications was not recorded though based on data from the Minnesota Heart Survey, less than $1 \%$ of our participants would have been expected to have been treated with lipid-lowering medications (Arnett et al., 2002).

\subsection{Data Analysis}

Participants with bipolar and unipolar affective disorders were analyzed in separate samples. Burden of manic and depressive morbidity were modeled as dependent variables in linear regression models with total cholesterol as the independent variable of interest and covariates for age, gender, and mood stabilizer use at intake. The distribution of residuals was assessed to verify an approximately normal distribution. A second-order polynomial regression model was applied to assess whether using a quadratic to model the effects of fasting serum cholesterol would provide a significantly better fit than a linear model. A sensitivity analysis individually assessed the impact of a number of other potential confounding variables: hypertension, diabetes mellitus, thyroid disease, and estimated weight loss during present episode (or maximum of one year). 


\section{RESULTS}

Demographic and clinical characteristics of our sample are detailed in Table 1. The median (mean; SD) percent of weeks with clinically significant depressive symptoms was 30.7 (37.6; $31.7)$ for the 66 participants with unipolar depression. The 65 participants with bipolar disorder spent a median (mean; SD) of $18.5(30.9 ; 32.0)$ and $1.4(4.5 ; 6.5)$ percent of weeks with depressive and manic symptoms, respectively. Age did not correlate with affective symptom burden. Female gender was associated with a higher mean proportion of depressive symptoms (36.6\% versus $11.1 \%$ ) among unipolar participants. There were no gender differences for manic or depressive symptom burden among bipolar participants.

When modeled in regression, no linear effect of cholesterol upon depressive symptom burden was seen for unipolar or bipolar participants, controlling for age, gender, and use of a mood stabilizer. Cholesterol did predict clinically significant manic symptoms. A significant, inverse linear effect of cholesterol on manic symptom burden was observed (standardized beta $=-0.36$, $p=0.01$ ), controlling for age, gender, and use of a mood stabilizer in the regression model. The results for these three primary models are detailed in Table 2. The partial correlation of cholesterol and manic symptom burden, adjusting for covariates, was -0.32 . When no other variables are modeled, cholesterol remained significantly correlated with manic symptom burden $(\mathrm{r}=-0.27, p<0.03)$.

In the sensitivity analysis, the relationship between cholesterol and subsequent manic symptom burden did not appear confounded by hypertension, diabetes mellitus, thyroid disease, or weight loss of more than 10 pounds during the present episode.

\section{DISCUSSION}

In this prospective cohort study, we identified a relationship between low cholesterol and subsequent manic symptomatology. Our finding of greater subsequent burden of manic symptoms among those with lower cholesterol supports prior case control and cross-sectional findings. We, however, failed to prospectively confirm previous findings of a relationship between low cholesterol and depressive symptoms. Previous studies on cholesterol and course of affective illness have focused on response to antidepressants or subsequent relapse. Our analysis is unique with its focus on overall burden of affective symptomatology in an observational study.

While our prospective cohort study boasts several advantages to prior case control and crosssectional studies, several limitations exist. The within-groups comparison in our study avoids the potential selection bias inherent to matching. However, our participants had varied durations of follow-up. We therefore used the proportion of time with affective symptoms to address this, but this approach assumes that the proportion of time with recorded affective symptoms is not influenced by duration of follow-up. Given that many participants were recruited during an acute affective episode, this assumption may over-estimate symptom burden for those lost to follow-up early. In review of our data, only $5 \%$ of participants were lost to follow-up within one year or less. Participants in this limited sample had greater depressive symptom burden but no greater manic symptom burden compared with those followed for a greater duration. Removal of these participants does not substantially change the results.

Cholesterol has been known to increase with age (Berns et al., 1988), and affective symptoms later in follow-up may occur in the setting of different cholesterol values from those initially recorded. Moreover, our laboratory assessment included only total cholesterol and fractions were not subsequently available for a more refined analysis. There is some evidence that values of cholesterol fractions may be of particular relevance. For instance, high-density lipoprotein 
has been correlated to metabolites of dopamine and serotonin in the cerebrospinal fluid of individuals after suicide attempt (Engstrom et al., 1995). Despite these limitations, our prospective cohort study demonstrates a temporal association between total cholesterol and subsequent burden of manic symptoms. These findings are consistent with and add to the prior literature.

Because the CDS focused on phenomenology and longitudinal course of illness in affective disorders, rigor in the ascertainment of affective diagnosis represents a notable strength of this study. While our cholesterol assessment was limited to a single assessment of total cholesterol, our diagnostic and phenomenological assessments were rigorous and ongoing. Our long period of follow-up after the determination of fasting cholesterol at index episode requires some understanding of cholesterol as a static or trait measure. However, the intake cholesterol must invariably have been influenced by state-dependent factors. Changes in appetite and weight represent cardinal features of affective disorders and many of our participants subjectively reported substantial weight loss within the episode on the SADS, which may influence cholesterol levels. While our participants were all recruited while seeking treatment for an acute episode, they may have had varying degrees of weight loss. We were only able to estimate weight loss retrospectively with a categorical variable, limiting our ability to completely control for state-dependent factors. If these state-dependent changes obscure our ability to accurately assess the attribute of interest, cholesterol as a trait-marker, we would perhaps expect a reduction in our ability to discern existing relationships, a bias toward the null hypothesis. We were nonetheless able to identify a statistically significant relationship between cholesterol and subsequent manic morbidity.

Cholesterol may influence affect through a variety of mechanisms. Cholesterol is a principal component of lipid rafts, microdomains on the cell membrane thought important in synaptic function through organization of signaling components (Gil et al., 2006). Depletion of cholesterol may have diffuse effects on neurotransmission, altering a variety of functions, with effects not limited to excitatory amino acid transport (Butchbach et al., 2004), gammaaminobutryic acid uptake and transmission (Sooksawate and Simmonds, 2001; Sooksawate and Simmonds, 2001), opioid signaling (Huang et al., 2007), N-methyl-D-aspartate receptor signaling (Frank et al., 2004; Abulrob et al., 2005), and serotonergic function. In the psychiatric literature, the most commonly discussed cholesterol-mediated effects involve serotonergic function (Scanlon et al., 2001; Golomb et al., 2002). Cholesterol may influence the function of membrane-bound serotonergic structures through alterations in membrane fluidity (Papakostas et al., 2003). Cholesterol depletion impairs the function of 5- $\mathrm{HT}_{1 \mathrm{~A}}$ and 5- $\mathrm{HT}_{7}$ receptors (Sjogren et al., 2006; Singh et al., 2007). Cholesterol also stabilizes the serotonin transporter and cholesterol depletion may reduce serotonin transporter activity (Scanlon et al., 2001). The possible interactions between cholesterol and such modulatory, serotonergic symptoms are almost certainly complex and may defy traditional, linear methods of explanation. Inconsistencies in published findings may suggest a complex relationship yet to be elucidated, consistent with the diversity of proposed physiological mediators. The convergence of further clinical research with expansion of scientific knowledge at the basic level will be critical to eventually elucidate a presumably complex relationship between cholesterol and affective symptomatology.

\section{Acknowledgments}

This study was funded by NIMH grant MH 25416. Dr. Fiedorowicz is supported by L30 MH075180-02, the Nellie Ball Trust Research Fund, and a NARSAD Young Investigator Award. He has received research support for participating in a colleague's investigator-initiated study with Eli Lilly. The authors have no potential conflicts of interest, financial or otherwise. The authors thank Carol Moss and Barbara Robb for assistance with data management as well as Myra Fiedorowicz and Lois Warren for assistance with manuscript editing. 


\section{REFERENCES}

Abulrob A, Tauskela JS, Mealing G, Brunette E, Faid K, Stanimirovic D. Protection by cholesterolextracting cyclodextrins: a role for N-methyl-D-aspartate receptor redistribution. Journal of Neurochemistry 2005;92:1477-1486. [PubMed: 15748165]

Arnett DK, McGovern PG, Jacobs DR Jr, Shahar E, Duval S, Blackburn H, Luepker RV. Fifteen-year trends in cardiovascular risk factors (1980-1982 through 1995-1997): the Minnesota Heart Survey. American Journal of Epidemiology 2002;156:929-935. [PubMed: 12419765]

Atmaca M, Kuloglu M, Tezcan E, Ustundag B, Bayik Y. Serum leptin and cholesterol levels in patients with bipolar disorder. Neuropsychobiology 2002;46:176-179. [PubMed: 12566933]

Beasley CL, Honer WG, Bergmann K, Falkai P, Lutjohann D, Bayer TA. Reductions in cholesterol and synaptic markers in association cortex in mood disorders. Bipolar Disorders 2005;7:449-455. [PubMed: 16176438]

Berns MA, de Vries JH, Katan MB. Determinants of the increase of serum cholesterol with age: a longitudinal study. International Journal of Epidemiology 1988;17:789-796. [PubMed: 3225086]

Bocchetta A, Chillotti C, Carboni G, Oi A, Ponti M, Del Zompo M. Association of personal and familial suicide risk with low serum cholesterol concentration in male lithium patients. Acta Psychiatrica Scandinavica 2001;104:37-41. [PubMed: 11437748]

Butchbach ME, Tian G, Guo H, Lin CL. Association of excitatory amino acid transporters, especially EAAT2, with cholesterol-rich lipid raft microdomains: importance for excitatory amino acid transporter localization and function. Journal of Biological Chemistry 2004;279:34388-34396. [PubMed: 15187084]

Cassidy F, Carroll BJ. Hypocholesterolemia during mixed manic episodes. European Archives of Psychiatry and Clinical Neuroscience 2002;252:110-114. [PubMed: 12192467]

Chung KH, Tsai SY, Lee HC. Mood symptoms and serum lipids in acute phase of bipolar disorder in Taiwan. Psychiatry and Clinical Neurosciences 2007;61:428-433. [PubMed: 17610669]

Coryell W, Schlesser M. Combined biological tests for suicide prediction. Psychiatry Research 2007;150:187-191. [PubMed: 17289156]

Coryell W, Solomon D, Turvey C, Keller M, Leon AC, Endicott J, Schettler P, Judd L, Mueller T. The long-term course of rapid-cycling bipolar disorder. Archives of General Psychiatry 2003;60:914920. [PubMed: 12963673]

Deisenhammer EA, Kramer-Reinstadler K, Liensberger D, Kemmler G, Hinterhuber H, Fleischhacker WW. No evidence for an association between serum cholesterol and the course of depression and suicidality. Psychiatry Research 2004;121:253-261. [PubMed: 14675744]

Diaz-Sastre C, Baca-Garcia E, Perez-Rodriguez MM, Garcia-Resa E, Ceverino A, Saiz-Ruiz J, Oquendo MA, de Leon J. Low plasma cholesterol levels in suicidal males: a gender- and body mass indexmatched case-control study of suicide attempters and nonattempters. Progress in Neuropsychopharmacology and Biological Psychiatry 2007;31:901-905.

Ellison LF, Morrison HI. Low serum cholesterol concentration and risk of suicide. Epidemiology 2001;12:168-172. [PubMed: 11246576]

Endicott J, Spitzer RL. A diagnostic interview: the schedule for affective disorders and schizophrenia. Archives of General Psychiatry 1978;35:837-844. [PubMed: 678037]

Endicott J, Spitzer RL. Use of the Research Diagnostic Criteria and the Schedule for Affective Disorders and Schizophrenia to study affective disorders. American Journal of Psychiatry 1979;136:52-56. [PubMed: 758828]

Engstrom G, Alsen M, Regnell G, Traskman-Bendz L. Serum lipids in suicide attempters. Suicide and Life-Threatening Behavior 1995;25:393-400. [PubMed: 8553420]

Fagiolini A, Frank E, Scott JA, Turkin S, Kupfer DJ. Metabolic syndrome in bipolar disorder: findings from the Bipolar Disorder Center for Pennsylvanians. Bipolar Disorders 2005;7:424-430. [PubMed: 16176435]

Fiedorowicz JG, Coryell WH. Cholesterol and suicide attempts: a prospective study of depressed inpatients. Psychiatry Research 2007;152:11-20. [PubMed: 17360043]

Fiedorowicz JG, Leon AC, Keller MB, Solomon DA, Rice JP, Coryell WH. Do risk factors for suicidal behavior differ by affective disorder polarity? Psychological Medicine 2008:1-9. 
Fiedorowicz JG, Palagummi NM, Forman-Hoffman VL, Miller del D, Haynes WG. Elevated prevalence of obesity, metabolic syndrome, and cardiovascular risk factors in bipolar disorder. Annals of Clinical Psychiatry 2008;20:131-137. [PubMed: 18633739]

Frank C, Giammarioli AM, Pepponi R, Fiorentini C, Rufini S. Cholesterol perturbing agents inhibit NMDA-dependent calcium influx in rat hippocampal primary culture. FEBS Letters 2004;566:2529. [PubMed: 15147862]

Gabriel A. Changes in plasma cholesterol in mood disorder patients: does treatment make a difference? Journal of Affective Disorders 2007;99:273-278. [PubMed: 16979243]

Ghaemi SN, Shields GS, Hegarty JD, Goodwin FK. Cholesterol levels in mood disorders: high or low? Bipolar Disorders 2000;2:60-64. [PubMed: 11254022]

Gil C, Cubi R, Blasi J, Aguilera J. Synaptic proteins associate with a sub-set of lipid rafts when isolated from nerve endings at physiological temperature. Biochemical and Biophysical Research Communications 2006;348:1334-1342. [PubMed: 16920068]

Glueck CJ, Tieger M, Kunkel R, Hamer T, Tracy T, Speirs J. Hypocholesterolemia and affective disorders. American Journal of Medical Science 1994;308:218-225.

Golier JA, Marzuk PM, Leon AC, Weiner C, Tardiff K. Low serum cholesterol level and attempted suicide. American Journal of Psychiatry 1995;152:419-423. [PubMed: 7864269]

Golomb BA, Tenkanen L, Alikoski T, Niskanen T, Manninen V, Huttunen M, Mednick SA. Insulin sensitivity markers: predictors of accidents and suicides in Helsinki Heart Study screenees. Journal of Clinical Epidemiology 2002;55:767-773. [PubMed: 12384190]

Huang P, Xu W, Yoon SI, Chen C, Chong PL, Liu-Chen LY. Cholesterol reduction by methyl-betacyclodextrin attenuates the delta opioid receptor-mediated signaling in neuronal cells but enhances it in non-neuronal cells. Biochemical Pharmacology 2007;73:534-549. [PubMed: 17141202]

Jow GM, Yang TT, Chen CL. Leptin and cholesterol levels are low in major depressive disorder, but high in schizophrenia. Journal of Affective Disorders 2006;90:21-27. [PubMed: 16324751]

Judd LL, Akiskal HS, Maser JD, Zeller PJ, Endicott J, Coryell W, Paulus MP, Kunovac JL, Leon AC, Mueller TI, Rice JA, Keller MB. Major depressive disorder: a prospective study of residual subthreshold depressive symptoms as predictor of rapid relapse. Journal of Affective Disorders 1998;50:97-108. [PubMed: 9858069]

Judd LL, Schettler PJ, Akiskal HS, Maser J, Coryell W, Solomon D, Endicott J, Keller M. Long-term symptomatic status of bipolar I vs. bipolar II disorders. Int J Neuropsychopharmacology 2003;6:127137.

Keller MB, Lavori PW, Friedman B, Nielsen E, Endicott J, McDonald-Scott P, Andreasen NC. The Longitudinal Interval Follow-up Evaluation. A comprehensive method for assessing outcome in prospective longitudinal studies. Archives of General Psychiatry 1987;44:540-548. [PubMed: 3579500]

Kopf D, Westphal S, Luley CW, Ritter S, Gilles M, Weber-Hamann B, Lederbogen F, Lehnert H, Henn FA, Heuser I, Deuschle M. Lipid metabolism and insulin resistance in depressed patients: significance of weight, hypercortisolism, and antidepressant treatment. Journal of Clinical Psychopharmacology 2004;24:527-531. [PubMed: 15349009]

Lindberg G, Rastam L, Gullberg B, Eklund GA. Low serum cholesterol concentration and short term mortality from injuries in men and women. British Medical Journal 1992;305:277-279. [PubMed: 1392858]

Maes M, Christophe A, Delanghe J, Altamura C, Neels H, Meltzer HY. Lowered omega3 polyunsaturated fatty acids in serum phospholipids and cholesteryl esters of depressed patients. Psychiatry Research 1999;85:275-291. [PubMed: 10333380]

Morgan RE, Palinkas LA, Barrett-Connor EL, Wingard DL. Plasma cholesterol and depressive symptoms in older men. The Lancet 1993;341:75-79.

Muldoon MF, Manuck SB, Matthews KA. Lowering cholesterol concentrations and mortality: a quantitative review of primary prevention trials. British Medical Journal 1990;301:309-314. [PubMed: 2144195]

Nakao M, Yano E. Relationship between major depression and high serum cholesterol in Japanese men. The Tohoku Journal of Experimental Medicine 2004;204:273-287. [PubMed: 15572853] 
Neaton JD, Blackburn H, Jacobs D, Kuller L, Lee DJ, Sherwin R, Shih J, Stamler J, Wentworth D. Serum cholesterol level and mortality findings for men screened in the Multiple Risk Factor Intervention Trial. Multiple Risk Factor Intervention Trial Research Group. Archives of Internal Medicine 1992;152:1490-1500. [PubMed: 1627030]

Olusi SO, Fido AA. Serum lipid concentrations in patients with major depressive disorder. Biological Psychiatry 1996;40:1128-1131. [PubMed: 8931915]

Oxenkrug GF, Branconnier RJ, Harto-Truax N, Cole JO. Is serum cholesterol a biological marker for major depressive disorder? American Journal of Psychiatry 1983;140:920-921. [PubMed: 6859316]

Pae CU, Kim JJ, Lee SJ, Lee C, Paik IH, Lee CU. Aberration of cholesterol level in first-onset bipolar I patients. Journal of Affective Disorders 2004;83:79-82. [PubMed: 15546649]

Papakostas GI, Iosifescu DV, Petersen T, Hamill SK, Alpert JE, Nierenberg AA, Rosenbaum JF, Fava M. Serum cholesterol in the continuation phase of pharmacotherapy with fluoxetine in remitted major depressive disorder. Journal of Clinical Psychopharmacology 2004;24:467-469. [PubMed: 15232350]

Papakostas GI, Petersen T, Mischoulon D, Hughes ME, Alpert JE, Nierenberg AA, Rosenbaum JF, Fava M. Serum cholesterol and serotonergic function in major depressive disorder. Psychiatry Research 2003;118:137-145. [PubMed: 12798978]

Papakostas GI, Petersen T, Sonawalla SB, Merens W, Iosifescu DV, Alpert JE, Fava M, Nierenberg AA. Serum cholesterol in treatment-resistant depression. Neuropsychobiology 2003;47:146-151. [PubMed: 12759558]

Partonen T, Haukka J, Virtamo J, Taylor PR, Lonnqvist J. Association of low serum total cholesterol with major depression and suicide. British Journal of Psychiatry 1999;175:259-262. [PubMed: 10645328]

Sagud M, Mihaljevic-Peles A, Pivac N, Jakovljevic M, Muck-Seler D. Platelet serotonin and serum lipids in psychotic mania. Journal of Affective Disorders 2007;97:247-251. [PubMed: 16820211]

Scanlon SM, Williams DC, Schloss P. Membrane cholesterol modulates serotonin transporter activity. Biochemistry 2001;40:10507-10513. [PubMed: 11523992]

Singh P, Paila YD, Chattopadhyay A. Differential effects of cholesterol and 7-dehydrocholesterol on the ligand binding activity of the hippocampal serotonin(1A) receptor: implications in SLOS. Biochemical and Biophysics Research Communications 2007;358:495-499.

Sjogren B, Hamblin MW, Svenningsson P. Cholesterol depletion reduces serotonin binding and signaling via human 5-HT(7(a)) receptors. European Journal of Pharmacology 2006;552:1-10. [PubMed: 17064686]

Solomon DA, Leon AC, Endicott J, Coryell WH, Mueller TI, Posternak MA, Keller MB. Unipolar mania over the course of a 20-year follow-up study. American Journal of Psychiatry 2003;160:2049-2051. [PubMed: 14594755]

Sooksawate T, Simmonds MA. Effects of membrane cholesterol on the sensitivity of the GABA(A) receptor to GABA in acutely dissociated rat hippocampal neurones. Neuropharmacology 2001;40:178-184. [PubMed: 11114396]

Sooksawate T, Simmonds MA. Influence of membrane cholesterol on modulation of the GABA(A) receptor by neuroactive steroids and other potentiators. British Journal of Pharmacology 2001;134:1303-1311. [PubMed: 11704651]

Spitzer RL, Endicott J, Robins E. Research diagnostic criteria: rationale and reliability. Archives of General Psychiatry 1978;35:773-782. [PubMed: 655775]

Swartz CM. Albumin decrement in depression and cholesterol decrement in mania. Journal of Affective Disorders 1990;19:173-176. [PubMed: 2145338]

Volek JS, Gomez AL, Love DM, Weyers AM, Hesslink R Jr, Wise JA, Kraemer WJ. Effects of an 8week weight-loss program on cardiovascular disease risk factors and regional body composition. European Journal of Clinical Nutrition 2002;56:585-592. [PubMed: 12173568] 


\section{Table 1}

Relevant demographic and clinical characteristics of bipolar and unipolar patients included in the analysis. The Longitudinal Interval Follow-up Evaluation (LIFE) Psychiatric Status Rating (PSR) was used to track weekly ratings of symptom levels. Participants with bipolar and unipolar disorder comprised separate samples and contrasts were not made across diagnostic groupings.

\begin{tabular}{|c|c|c|}
\hline & Unipolar & Bipolar \\
\hline $\mathrm{N}=$ & 66 & 65 \\
\hline \multicolumn{3}{|l|}{ Intake Data } \\
\hline Mean Age at Intake & 34.6 & 33.9 \\
\hline Inpatient & $95 \%$ & $98 \%$ \\
\hline Percent Female & $65 \%$ & $55 \%$ \\
\hline Mean Cholesterol (mg/dL) & 203 & 196 \\
\hline Hypertension & $17 \%$ & $15 \%$ \\
\hline Diabetes mellitus & $5 \%$ & $2 \%$ \\
\hline Thyroid disorder & $21 \%$ & $32 \%$ \\
\hline Percent on Mood Stabilizer & $3 \%$ & $54 \%$ \\
\hline $\begin{array}{l}\text { Intra-episode weight loss of } \\
\text { more than } 10 \text { pounds }\end{array}$ & $36 \%$ & $31 \%$ \\
\hline \multicolumn{3}{|l|}{ Prospective Data } \\
\hline $\begin{array}{l}\text { Median Percent of Weeks } \\
\text { Depressed }\end{array}$ & $31 \%$ & $18 \%$ \\
\hline $\begin{array}{l}\text { Median Percent of Weeks } \\
\text { Manic }\end{array}$ & $0 \%$ & $1.4 \%$ \\
\hline Median PSR Follow-up & 20 years & 20 years \\
\hline
\end{tabular}




\section{Table 2}

Primary linear regression analyses examined the relationship between our variable of interest, intake cholesterol and depressive or manic symptom burden. Standardized slope values and levels of significance are reported for each variable in the model. The partial correlation of cholesterol and manic symptom burden, adjusting for covariates, was -0.32 .

\begin{tabular}{|c|c|c|c|}
\hline Model/Variable & $\begin{array}{c}\mathbf{R}^{2} \\
\text { Model }\end{array}$ & $\begin{array}{c}\text { Standardized } \\
\text { Beta }\end{array}$ & $\boldsymbol{P}$ \\
\hline $\begin{array}{l}\text { 1. Depressive symptom burden in major } \\
\text { depression }\end{array}$ & 0.197 & & \\
\hline Cholesterol & & -0.004 & 0.97 \\
\hline Age & & 0.204 & 0.09 \\
\hline Female Gender & & 0.408 & $<0.01$ \\
\hline Mood Stabilizer Use & & -0.093 & 0.43 \\
\hline $\begin{array}{l}\text { 2. Depressive symptom burden in bipolar } \\
\text { disorders }\end{array}$ & 0.093 & & \\
\hline Cholesterol & & 0.088 & 0.54 \\
\hline Age & & 0.063 & 0.65 \\
\hline Female Gender & & -0.031 & 0.81 \\
\hline Mood Stabilizer Use & & -0.269 & 0.04 \\
\hline $\begin{array}{l}\text { 3. Manic symptom burden in bipolar } \\
\text { disorders }\end{array}$ & 0.118 & & \\
\hline Cholesterol & & -0.362 & 0.01 \\
\hline Age & & 0.190 & 0.17 \\
\hline Female Gender & & 0.100 & 0.42 \\
\hline Mood Stabilizer Use & & 0.036 & 0.78 \\
\hline
\end{tabular}

